EXTENDED REPORT

\title{
Orthoptic status before and immediately after heroin detoxification
}

\author{
A Y Firth, S Pulling, M P Carr, A Y Beaini
}

Br J Ophthalmol 2004;88:1186-1190. doi: 10.1136/bjo.2003.032334

See end of article for authors' affiliations

.....................

Correspondence to: Alison Y Firth, Academic Unit of Ophthalmology and Orthoptics, O Floor, Royal Hallamshire Hospital, Glossop Road, Sheffield S10 2JF, UK; a.firth@sheffield.ac.uk

Accepted for publication 20 February 2004

\begin{abstract}
Aim: To determine whether changes in orthoptic status take place during withdrawal from heroin and/or methadone.

Method: A prospective study of patients, using a repeated measures design, attending a 5 day naltrexone compressed opiate detoxification programme.

Results: 83 patients were seen before detoxification (mean age 27.1 (SD 4.6) years) and 69 after detoxification. The horizontal angle of deviation became less exo/more eso at distance $(p<0.001)$ but no significant change was found at near $(p=0.069)$. Stereoacuity, visual acuity, and convergence were found to be reduced in the immediate post-detoxification period. Prism fusion range, refractive error, subjective accommodation, and objective accommodation at $33 \mathrm{~cm}$ did not reduce but a small decrease was found in objective accommodation at $20 \mathrm{~cm}$.

Conclusions: The eso trend found in these patients may be responsible for the development of acute concomitant esotropia in some patients undergoing heroin detoxification. However, the mechanism for this trend does not appear to be caused by divergence insufficiency or sixth nerve palsy.
\end{abstract}

\section{METHODS}

Patients were recruited over 9 consecutive weeks, from an inpatient heroin detoxification centre at which a 5 day naltrexone compressed opiate detoxification protocol is used (table 1). ${ }^{8}$ Each patient was seen twice-once before detoxification (day 1) and once before discharge (day 5). Information sheets and consent forms were sent to patients before admission. Consent was obtained on the day of admission. Exclusion criteria were: presbyopes or prepresbyopes (4l years of age and above); severe learning difficulties; neurological disorders; visual acuity of less than 6/60 in both eyes; visual acuity of less than 3/60 in either eye. Staff from the centre volunteered as control participants and followed the same exclusion criteria and procedure as below. The study was approved by the local research ethics committee.

On the day of admission (day 1), before sedation, consenting patients underwent examination by one researcher (AYF). All tests were performed with refractive correction, if worn regularly. The order of testing was as in the order of the description below. Details of other drug use before admission and mode of opioid use were taken from hospital notes.
For patients admitted in weeks 3-9, the time since the last use and the time until the next heroin or methadone dose would usually be taken were noted.

A cover test was performed at $33 \mathrm{~cm}$ and 6 metres. If a subject was found to have a decompensating deviation at near, the binocular visual acuity (BVA) was recorded. Horizontal prism fusion range to a light target with Bagolini glasses, was measured noting the break point (point at which fusion failed). For analysis, the angle of deviation (minus value for exo deviations and plus for eso deviations) was added to the value of the prism at break point (absolute value). In manifest strabismus the prism fusion range was not undertaken. Stereoacuity was assessed using the TNO stereotest. Prism cover test measurements were recorded; and on right gaze and left gaze at 6 metres for subjects tested in weeks 4-9. Monocular near visual acuity was measured using a reduced Snellen chart and distance visual acuity at $100 \%$ and $10 \%$ contrast using a Bailey-Lovie chart. Ocular movements were assessed fixing a light and using a cover test. Pupil size was assessed with a millimetre rule fixing the examiner's eye at approximately $50 \mathrm{~cm}$. Using the RAF rule, convergence was recorded and subjective accommodation for both eyes open; each eye monocularly; and both eyes open repeated. Objectively, refractive state was measured in either eye (with both eyes open) using the Nikkon open field autorefractor SRW 5000 while the subject was fixing at 6 metres (with and without fogging lens); $33 \mathrm{~cm}$, and $20 \mathrm{~cm}$ to a $6 / 6$ target or smallest letter able to be seen.

On the morning of day 5 the same protocol was used for performing the clinical tests, but some subjects were unwilling or unable to complete testing because of tiredness or sickness. Patients were asked if they had noticed any problems with vision. The same examiner (AYF) repeated the tests but did not refer to previous data sheets until testing was completed. All tests were carried out in the same area on both days under normal room lighting conditions, with the

Abbreviations: BVA, binocular visual acuity; MSE, mean spherical equivalent; MW, Mann-Whitney; WSRT, Wilcoxon signed ranks test 


\begin{tabular}{|c|c|c|}
\hline Time & Medication & Purpose \\
\hline $\begin{array}{l}\text { Afternoon day } 1 \\
\text { through to midnight } \\
\text { day } 3\end{array}$ & $\begin{array}{l}\text { Zuclopenthixol (Clopixol) } 10 \mathrm{mg} \text { and diazepam (Valium) } \\
10 \mathrm{mg} \text { orally, then zuclopenthixol } 4 \times 10 \mathrm{mg} \text { daily with } \\
\text { another four doses as and if required and diazepam } \\
4 \times 10 \mathrm{mg} \text { daily. Trazodone hydrochloride } 150-300 \mathrm{mg} \text { nightly. } \\
\text { Lorazepam (Ativan) up to } 4 \mathrm{mg} \text { every } 6 \text { hours; chlorpromazine } \\
50-100 \mathrm{mg} \text { every } 6 \text { hours for those with high tolerance to the } \\
\text { standard medication, or where patients have been abusing } \\
\text { benzodiazapines. Amylobarbitone/quinalbarbitone (Tiunal) } \\
100 \mathrm{mg}-200 \mathrm{mg} \text { every } 6 \text { hours if further top up needed }\end{array}$ & $\begin{array}{l}\text { Additional } \\
\text { medication if } \\
\text { sedation not } \\
\text { adequate }\end{array}$ \\
\hline Day 4 & Challenge dose of oral $25 \mathrm{mg}$ naltrexone (Nalorex) & $\begin{array}{l}\text { To flush out } \\
\text { remaining opiates }\end{array}$ \\
\hline Day 5 & Full naltrexone (Nalorex) dose (50 mg) & $\begin{array}{l}\text { To build block against } \\
\text { opiate use }\end{array}$ \\
\hline Throughout & $\begin{array}{l}\text { Diclofenac sodium (Voltarol); hyoscine butylbromide } \\
\text { (Buscopan); ranitidine (Zantac); procyclidine (Kemadrin); } \\
\text { prochlororperazine (Stemetil), metoclopramide (Maxolon) } \\
\text { as required. }\end{array}$ & $\begin{array}{l}\text { To relieve symptoms } \\
\text { or side effects of other } \\
\text { medication }\end{array}$ \\
\hline
\end{tabular}

exception of three cases on day 5 who were unwell; limited testing took place in these patients' rooms.

\section{Analysis}

Near visual acuity ${ }^{9}$ and prism measurements are ordinal data and non-parametric tests used (Wilcoxon signed ranks test (WSRT); Mann-Whitney (MW); Friedman test). Parametric analysis involved the use of $t$ test (paired or unpaired) and analysis of variance. Spearman's test was used to determine correlations and multivariate regression. Refractive data were converted to mean spherical equivalent (MSE) for analysis.

\section{RESULTS}

Eighty three subjects were seen before detoxification, mean age 27.1 (SD 4.6) years (range 18-40.5). Fifty five were currently heroin users; 18 used methadone but topped up with heroin; and 10 were currently using methadone only. The mode of heroin use was or had been smoking 35; intravenously 25; both 20 . The remaining three subjects used methadone and had rarely used heroin. Sixty nine subjects were examined on day 5. Ten subjects formed the control group, mean age 29.5 (7.4) years (range 20-39).

Seven patients were myopic and two hypermetropic. One patient had had a blow to his left eye which resulted in intermittent diplopia. One patient reported diplopia following a previous detoxification attempt and one patient reported diplopia if he started to withdraw from heroin.

Table 2 Number of patients using heroin substitutes and non-prescribed drugs

\begin{tabular}{lll}
\hline & Regular & Irregular/occasional/in past \\
\hline Methadone & 28 & 55 \\
DF118 & 5 & 36 \\
Cocaine & 47 & 3 \\
Cannabis & 46 & 1 \\
LSD & 26 & 1 \\
Ectasy & 38 & 0 \\
Amphetamines & 15 & 1 \\
Temazepam & 24 & 16 \\
Diazepam & 26 & 20 \\
Nitrazepam & 8 & 6 \\
Codeine & 0 & 3 \\
Zopiclone & 0 & 5 \\
Amitryptiline & 0 & 1 \\
\hline
\end{tabular}

The mean time from the last dose of heroin was 8.44 (7.76) hours $(n=53)$ and all except nine would normally have used it again by the time of examination. The use of nonprescribed drugs was frequent and listed in table 2 along with prescribed heroin substitutes.

Fifty of 69 subjects seen on day 5 reported ocular symptoms. While the majority $(\mathrm{n}=22)$ noted these on day 4 , others noted them occurring across the other days (mainly days $1-3$ ). On day 5, 26 felt that symptoms were improving, one worsening, and there was no change in the others. Symptoms were blur all distances $\mathrm{n}=12$; blur near only $\mathrm{n}=1$; blur distance only $\mathrm{n}=4$; diplopia $\mathrm{n}=14$; blur and diplopia $\mathrm{n}=19$.

\section{Cover test and angle of deviation}

Cover test findings are shown in table 3 and angles of deviations in table 4 . The angle was significantly different between patients on day 1 and controls $(p=0.005$, MW) for near but not for distance ( $p=0.055 \mathrm{MW})$. Median values and ranges for horizontal prism cover test measurements for the patient group for near and distance are shown in table 4 . The change in horizontal angle of deviation for paired subjects between day $\mathrm{l}$ and day 5 was not significant $(\mathrm{p}=0.069)$ for near but was significant for distance $(p<0.001)$, demonstrating a change in the eso direction. There was no difference between those withdrawing from heroin, methadone, or a combination of the two, and no effects from other recreational drugs taken.

Primary position distance and lateral gaze measurements for 38 subjects where data were complete for days 1 and 5 are given in table 4 . For day 1 and for day 5 a significant difference was shown between primary position, right and left gaze (both $\mathrm{p}<0.01$; Friedman). To determine whether there was a change in the degree of incomitance, the change in the angle between primary position and side gaze between day $\mathrm{l}$ and day 5 was considered and resultant measurements compared. Right gaze measurements showed a median change of $+2 \Delta$ (range $-12 \Delta$ to $+10 \Delta$ ), not significant $(\mathrm{p}=0.098)$, and left gaze measurements showed a median change of $+2 \Delta$ (range $-8 \Delta$ to $+10 \Delta)$, significant $(\mathrm{p}=0.01)$. Only one subject in the patient group demonstrated a vertical deviation in the primary position, this was the patient who gave the history of injury; no vertical deviation was detected on day $\mathrm{l}$ ( $\mathrm{N}$ : $20 \Delta \mathrm{X}$ for near; $2 \Delta \mathrm{X}$ for distance) but on day $5 \mathrm{a}$ vertical element was present at both distances (N: 20 $\Delta X \mathrm{XT}$ $4 \Delta$ RHT near; $\phi 6 \Delta$ RHT distance). 
Table 3 Cover test findings (numbers refer to number of patients)

\begin{tabular}{|c|c|c|c|c|c|c|}
\hline & Controls & Day 1 & Day 5 & Controls & Day 1 & Day 5 \\
\hline & Near & Near & Near & Distance & Distance & Distance \\
\hline$E$ & 2 & 9 & 19 & 1 & 9 & 18 \\
\hline$E(T)$ & 0 & 0 & 0 & 0 & 0 & 5 \\
\hline ET & 0 & 0 & 1 & 0 & 0 & 16 \\
\hline$x$ & 7 & 59 & 37 & 5 & 55 & 14 \\
\hline$X(T)$ & 0 & 12 & 7 & 0 & 2 & 0 \\
\hline XT & 0 & 0 & 2 & 0 & 1 & 0 \\
\hline 0 & 1 & 3 & 3 & 4 & 16 & 13 \\
\hline Total & 10 & 83 & 69 & 10 & 83 & 66 \\
\hline
\end{tabular}

\section{Prism fusion range}

Median values for the total fusion range for control subjects were $41.5 \Delta$ for near (range 24-53) and 23 $\Delta$ for distance (range 8-33). For the patient group total amplitudes were $26 \Delta$ near (range $2-70 ; \mathrm{n}=69$ ) and $18 \Delta$ distance (range 4-34; $\mathrm{n}=68$ ) on day $\mathrm{l}$ and $24 \Delta$ near (range $2-57 ; \mathrm{n}=45$ ) and $14.5 \Delta$ (range $3-39 ; \mathrm{n}=32$ ) on day 5 . The range was significantly higher for control subjects compared with patients on day $\mathrm{l}$ at near but not distance $(\mathrm{p}=0.013$ and $p=0.494$ respectively, MW). The difference at near was due to the divergent range being lower in the patient group when the baseline angle of deviation was taken into account.

No statistical difference existed in the total prism fusion range between day 1 and day 5 for near or distance either when all patients were considered $(p=0.452 ; p=0.063$ respectively, MW), or when pairing data where complete for both examinations $(p=0.189 ; p=0.45$ respectively, WSRT), and no significant change in absolute divergence occurred at distance fixation (median day $1-6 \Delta$; median day $5-7 \Delta ; \mathrm{p}=0.806$. WSRT). The control subjects showed a similar absolute range of divergence at distance (median $6 \Delta$ ) to the patient group $(\mathrm{p}=0.791, \mathrm{MW})$.

\section{Stereoacuity}

No difference was found between control subjects and patients on day $\mathrm{l}$ (median 60 seconds of arc, $\mathrm{p}=0.752$, $\mathrm{MW})$. Twenty nine of 60 patients for whom measures were available on both days showed a reduced score $(\mathrm{p}<0.0001$. WSRT). Of the 12 patients showing an intermittent exotropia at near on day 1, 10 achieved 60 seconds of arc or better. All had normal binocular visual acuities.

\section{Ocular motility}

Ocular motility was within normal limits on day 1 in 54 subjects. Twenty four showed very small limitations of abduction $(<-1)$ and five had other defects (four cases: slight unilateral or bilateral superior oblique underactions, one case: slight underaction left superior rectus $(-1)$ following injury). Of those tested on day $5(\mathrm{n}=60), 35$ were normal, 19 showed very small limitation(s) of abduction, four subjects had developed signs of superior oblique underaction(s), and one inferior oblique underaction. The one case with underaction in laevoelevation showed an increase in this $(-2)$.

\section{Visual acuity, convergence, and accommodation}

Near visual acuity had a median of $0.00(6 / 6)$ for both right and left eyes for control subjects and patients on day 1 and 0.2 for patients on day 5. A significant decline was shown between day 1 and day $5(\mathrm{p}<0.001$ right eye; $\mathrm{p}=0.006 \mathrm{left}$ eye. WSRT). Distance visual acuity and low contrast acuity also significantly declined in the absence of any change in refractive error (table 5). Convergence, accommodation and pupil size results are shown in table 5 .

\section{Medication}

The only statistically significant finding was a negative correlation between the dosage of Clopixol and the change in the eso direction $(r=-0.272 ; \mathrm{p}=0.033)$. The $r^{2}$ value is low.

\section{DISCUSSION}

The main finding of the study was the change in the distance angle of deviation, demonstrating a change in the eso direction. The most obvious mechanisms for this are sixth nerve involvement and divergence insufficiency. When this trend became apparent, lateral gaze measurements were added to the testing regime (week 4 onwards). The median change in side gaze measure, however, was only $2 \Delta$ and this is not considered clinically indicative of sixth nerve weakness. Also there was a tendency for a change in the eso direction on side measures before detoxification.

Subtle sixth nerve involvement has been implicated in divergence paralysis ${ }^{10}$ because of raised intracranial pressure and in the presence of papilloedema and the condition has been reported with ingestion ${ }^{11}$ and withdrawal of diazepam. ${ }^{12}$

Table 4 Horizontal prism cover test measurements

\begin{tabular}{|c|c|c|c|c|c|c|c|c|c|}
\hline & \multicolumn{3}{|l|}{ Day 1} & \multicolumn{3}{|l|}{ Day 1} & \multicolumn{3}{|l|}{ Day 5} \\
\hline & Controls & Median & Range & Patients & Median & Range & Patients & Median & Range \\
\hline Near & $n=10$ & $3 \Delta \mathrm{PBln}$ & $\begin{array}{l}8 \Delta \text { PBln to } \\
8 \Delta \text { PBOut }\end{array}$ & $n=82$ & $8 \Delta \mathrm{PBln}$ & $\begin{array}{l}25 \Delta \text { PBIn to } \\
35 \Delta \text { PBOut }\end{array}$ & $n=67$ & $6 \Delta \mathrm{PBln}$ & $\begin{array}{l}30 \Delta \text { PBIn to } \\
18 \Delta \text { PBOut }\end{array}$ \\
\hline Distance & $n=10$ & $1.5 \Delta \mathrm{PBln}$ & $\begin{array}{l}2 \Delta \text { PBln to } \\
4 \triangle \text { PBOut }\end{array}$ & $n=83$ & $2 \Delta \mathrm{PBln}$ & $\begin{array}{l}12 \Delta \text { PBIn to } \\
4 \Delta \text { PBOut }\end{array}$ & $n=66$ & $4 \triangle \mathrm{PBOut}$ & $\begin{array}{l}14 \Delta \text { PBln to } \\
16 \Delta \text { PBOut }\end{array}$ \\
\hline Primary position & & & & $n=38$ & $2 \Delta \mathrm{PBln}$ & $\begin{array}{l}10 \triangle \mathrm{PB} \text { In to } \\
4 \Delta \mathrm{PBOut}\end{array}$ & $n=38$ & $4 \Delta \mathrm{PBOut}$ & $\begin{array}{l}14 \Delta \text { PBIn to } \\
16 \Delta \text { PBOut }\end{array}$ \\
\hline Right gaze & & & & $n=38$ & $1.5 \Delta \mathrm{PB} / \mathrm{n}$ & 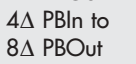 & $n=38$ & $8 \Delta$ PBOut & $\begin{array}{l}12 \Delta \text { PBln to } \\
18 \Delta \text { PBOut }\end{array}$ \\
\hline Left gaze & & & & $n=38$ & $2 \Delta \mathrm{PB} / \mathrm{n}$ & $\begin{array}{l}6 \Delta \mathrm{PB} \text { In to } \\
8 \Delta \mathrm{PBOut}\end{array}$ & $n=38$ & $7 \Delta \mathrm{PBOut}$ & $\begin{array}{l}14 \Delta \text { PBIn to } \\
18 \Delta \text { PBOut }\end{array}$ \\
\hline
\end{tabular}

$\mathrm{PBIn}=$ prism base-in; $\mathrm{PBOut}=$ prism base-out; $\Delta=$ prism dioptres 
Table 5 Test results (mean (SD))

\begin{tabular}{|c|c|c|c|c|c|c|}
\hline \multirow[b]{2}{*}{ Test and notation } & \multirow[b]{2}{*}{ Controls } & \multirow{2}{*}{$\begin{array}{l}\text { All patients } \\
\text { completed day } 1\end{array}$} & \multirow{2}{*}{$\frac{p \text { Values }}{\text { Control } v \text { day } 1}$} & \multirow{2}{*}{$\begin{array}{l}\text { Day } 1 \text { (paired } \\
\text { data) }\end{array}$} & \multirow[b]{2}{*}{ Day 5 (paired data) } & \multirow{2}{*}{$\begin{array}{l}p \text { Value and } \\
\text { number of pairs }\end{array}$} \\
\hline & & & & & & \\
\hline Distance RVA (logMAR) & $-0.01(0.08)$ & $0.00(0.24)$ & 0.563 & $0.01(0.27)$ & $0.11(0.15)$ & $\begin{array}{l}0.001^{*} \\
55\end{array}$ \\
\hline Distance LVA (logMAR) & $0.02(0.09)$ & $0.09(0.03)$ & 0.833 & $0.02(0.25)$ & $0.13(0.22)$ & $\begin{array}{l}<0.001^{*} \\
55\end{array}$ \\
\hline Low contrast RVA (logMAR) & $0.22(0.1)$ & $0.25(0.16)$ & 0.492 & $0.24(0.16)$ & $0.32(0.16)$ & $\begin{array}{l}<0.001^{*} \\
49\end{array}$ \\
\hline Low contrast LVA (logMAR) & $0.25(0.11)$ & $0.25(0.16)$ & 0.941 & $0.24(0.14)$ & $0.3(0.15)$ & $\begin{array}{l}0.003^{*} \\
48\end{array}$ \\
\hline Pupil size RE (mm) & $4.65(0.66)$ & $4.52(1.22)$ & 0.745 & $4.65(1.24)$ & $4.96(1.14)$ & $\begin{array}{l}0.109 \\
62\end{array}$ \\
\hline Pupil size LE (mm) & $4.65(0.67)$ & $4.53(1.23)$ & 0.781 & $4.67(1.25)$ & $4.93(1.21)$ & $\begin{array}{l}0.194 \\
62\end{array}$ \\
\hline Convergence $(\mathrm{cm})$ & $7(1.56)$ & $7.72(3.56)$ & 0.531 & 7.49 (3.83) & $10.96(10.11)$ & $\begin{array}{l}0.012^{*} \\
53\end{array}$ \\
\hline Accommodation RE $(\mathrm{cm})$ & $15.3(5.58)$ & $15.29(5.52)$ & 0.995 & $14.63(5.14)$ & $15.69(5.31)$ & $\begin{array}{l}0.267 \\
48\end{array}$ \\
\hline Accommodation LE (cm) & $15.9(7.4)$ & $15.08(5.18)$ & 0.658 & $14.61(4.72)$ & $15.69(4.98)$ & $\begin{array}{l}0.179 \\
49\end{array}$ \\
\hline Accommodation $\mathrm{BE}(\mathrm{cm})$ & $13.1(3.2)$ & $12.93(4.58)$ & 0.908 & $13.22(4.85)$ & $14.15(6.68)$ & $\begin{array}{l}0.278 \\
53\end{array}$ \\
\hline Accommodation BE repeated $(\mathrm{cm})$ & $14.5(6.85)$ & $12.2(4.16)$ & 0.139 & $12.24(4.2)$ & $13(5.1)$ & $\begin{array}{l}0.356 \\
42\end{array}$ \\
\hline MSE with fogging lens RE (D) & $+0.05(0.23)$ & $+0.16(0.85)$ & 0.688 & $+0.06(0.63)$ & $+0.26(0.69)$ & $\begin{array}{l}0.129 \\
28\end{array}$ \\
\hline MSE with fogging lens LE (D) & $+0.46(0.34)$ & $+0.14(0.63)$ & 0.14 & $+0.08(0.44)$ & $+0.22(0.53)$ & $\begin{array}{l}0.093 \\
26\end{array}$ \\
\hline MSE 6 metres RE (D) & $+0.08(0.45)$ & $+0.1(0.75)$ & 0.929 & $-0.02(0.51)$ & $0.068(0.68)$ & $\begin{array}{l}0.308 \\
36\end{array}$ \\
\hline MSE 6 metres LE (D) & $+0.25(0.54)$ & $0.11(0.56)$ & 0.477 & $+0.18(0.49)$ & $0.19(0.67)$ & $\begin{array}{l}0.851 \\
35\end{array}$ \\
\hline MSE 33 cm RE (D) & $-2.34(0.18)$ & $-2.34(0.58)$ & 1.00 & $-2.44(0.36)$ & $-2.35(0.55)$ & $\begin{array}{l}0.373 \\
30\end{array}$ \\
\hline MSE $33 \mathrm{~cm}$ LE (D) & $-2.4(0.29)$ & $-2.38(0.44)$ & 0.896 & $-2.37(0.43)$ & $-2.26(0.85)$ & $\begin{array}{l}0.443 \\
29\end{array}$ \\
\hline MSE 20 cm RE (D) & $-3.74(0.42)$ & $-3.9(0.67)$ & 0.456 & $-4.05(0.63)$ & $-3.49(0.81)$ & $\begin{array}{l}0.003^{*} \\
26\end{array}$ \\
\hline MSE $20 \mathrm{~cm}$ LE (D) & $-3.86(0.59)$ & $-3.88(0.67)$ & 0.924 & $-3.87(0.56)$ & $-3.28(0.77)$ & $\begin{array}{l}<0.001^{*} \\
26\end{array}$ \\
\hline
\end{tabular}

Jacobson ${ }^{13}$ reports two series of primary and secondary cases of divergence insufficiency, median absolute divergence amplitudes were $2 \Delta$ and $4 \Delta$ respectively. Median values in this current study for 6 metres were $6 \Delta$ on day 1 and $7 \Delta$ on day 5, and no significant change was found. However, although subjects who developed esophoria and intermittent esotropia were included in the day 5 measurements, subjects where a constant manifest deviation developed did not have their angle corrected and the test performed. The level of divergence was comparable to the control group on both day 1 and day 5 of the study at distance. The lower level of divergence at near could be an artefact in that 15 of the patient group and no controls diverged to as much as their angle of deviation and so had a "negative" level of divergence. This phenomenon is often seen clinically in exophoric patients and is possibly a carryover of tenacious proximal convergence.

Following a single dose of lorazepam $0.038 \mathrm{mg} / \mathrm{kg}$ SpeegSchatz et $a l^{14}$ found a change of $+2.8 \Delta$ at distance fixation and reduction of the near point of convergence by a mean of $6.3 \mathrm{~cm}$ without any change in subjective accommodation. The effect was thought to be due to muscle relaxation. Two drugs in the phenothiazine group have also been linked to diplopia: olanzapine ${ }^{15}$ causing a concomitant esotropia and prochlorperazine $^{16}$ causing sixth nerve palsy. However, no links were found between lorazepam or phenothiazine doses and changes in distance angle in this study.

No differences were found in subjective accommodation between controls and patients, before and after detoxification, and no fatigue between the first and last measure. This is contrary to Perez et al's findings ${ }^{17}$; they reported reduced subjective accommodation in a group of heroin users in a detoxification centre. However, the method of detoxification is not given, nor stage during detoxification at which measurements were taken. "Visual disturbances" or "blurred vision" are listed as side effects for several of the medications used in this withdrawal programme; however, there was no evidence of reduced accommodation on subjective testing and only weak evidence for reduced objective accommodation (table 5).

The number of subjects reporting blur and/or diplopia was $72.5 \%$, higher than the $10 \%$ to $33.3 \%$ previously reported. ${ }^{2}$ This may be due to the method of detoxification. Kowal et al ${ }^{5}$ reported that diplopia was more common following rapid detoxification (using naltrexone) and this has also been suggested ${ }^{4}$ as causing a "physical or psychic shock" which precedes the onset of acute concomitant esotropia. ${ }^{18}$ In the current study, cover test findings showed intermittent esotropia to be present in 10 of 14 subjects complaining of diplopia. In 17 patients diplopia was accompanied by blur, and only seven of these demonstrated a manifest deviation. This is suggestive that some patients are interpreting blur as diplopia. Pupil size was similar before and after detoxification and so could not account for blur.

Visual acuity reduction was not due to refractive changes. In a previous study ophthalmoscopic examination was found to be normal following withdrawal. ${ }^{3}$ Opioid receptors have been identified in the ganglion cell layer of the human 
retina $^{19}$ and withdrawal from opiates may affect the firing rate or neurotransmission of these cells.

Opioid receptors in many parts of the brain have yet to be identified. The onset of exotropia on intake ${ }^{6}$ of heroin and esotropia on withdrawal ${ }^{4-6}$ and the larger exo deviations at near in the patient group is suggestive of an active mechanism. Although the number of participants in the control group was small, the angle of deviation in the group compares well with previously published literature. ${ }^{20}$ The main difference found was that, despite the presence of eso deviations in nine of 83 patients and only two of 10 controls (no statistical difference shown by $\chi^{2}$ testing for these figures), the angle of deviation in the patient group was significantly greater and this difference was in the exo direction. This was statistically significant for near only, although a trend towards this could also be said to exist in the distance, results just failing to reach the $5 \%$ level of significance $(p=0.055)$. The range of angles was also much higher in the patient group. It has been hypothesised that there is direct involvement of mid brain neurons in the onset of acute concomitant esotropia, ${ }^{21}$ and it is possible that cells involved in the near or far response $\mathrm{e}^{22-25}$ are affected such that the equilibrium between convergence and divergence is altered as tolerance to opioids increases leading to an imbalance on withdrawal.

This study has demonstrated an eso trend at distance fixation following detoxification. The mechanism does not appear to be divergence insufficiency or sixth nerve involvement, nor does it appear to be related to medication used during this detoxification programme. The mechanism remains speculative. However, where adult patients present with distance esotropia, or a history of intermittent diplopia which has now become constant and esotropia is present, the history should include questions pertaining to drug abuse.

\section{ACKNOWLEDGEMENTS}

Our thanks go to staff and patients at Detox 5 for their help in carrying out the study, and to colleagues for helpful comments on the manuscript.

\section{Authors' affiliations}

A Y Firth, Academic Unit of Ophthalmology and Orthoptics, University of Sheffield, Sheffield, UK
S Pulling, M P Carr, A Y Beaini, Detox 5, Harrogate Clinic, Ripon Road, Harrogate, UK

\section{REFERENCES}

1 Himmelsbach CK. The morphine abstinence syndrome, its nature and treatment. Ann Intern Med 1941:829-39.

2 Ream NW, Robinson MG, Richter RW, et al. Opiate dependence and acute abstinence. In:Richter RW. Medical aspects of drug abuse. Hagerstown, MD: Harper and Row, 1975:81-123.

3 Thomas M, Cosgriff MC. Anisocoria in heroin withdrawal. Arch Neurol 1973;29:200-1.

4 Firth AY. Heroin withdrawal as a possible cause of acute concomitant esotropia in adults. Eye 2001;15:189-92.

5 Kowal L, Mee J, Nadkarni S, et al. Acute esotropia in heroin withdrawal: a case series. Binocul Vis Strabismus Q 2003;18:163-6.

6 Sutter FKP, Landau K. Heroin and strabismus. Swiss Med Wkly 2003; 133:293-4.

7 Iqbal N. Heroin use, diplopia, largactil. Saudi Med J 2000;21:1194

8 Beaini AY, Johnson TS, Langstaff P, et al. A compressed opiate detoxification regime with naltrexone maintainance: patient tolerance, risk assessment and abstinence rates. Addiction Biology 2000;5:451-62.

9 Moseley MJ, Jones HS. Visual acuity: calculating appropriate averages. Acta Ophthalmol 1993:71:296-300

10 Kirkham TH, Bird AC, Sanders MD. Divergence paralysis with raised intracranial pressure. Br J Ophthalmol 1972;56:776-82.

11 Arai M, Fujii S. Divergence paralysis associated with ingestion of diazepam. J Neurol 1990;237:45-6.

12 Hargrave MA. An odd cause of squint. Med J Aust 1972;2:967.

13 Jacobson DM. Divergence insufficiency revisited. Arch Ophthalmol 2000;1 18:1237-41.

14 Speeg-Schatz Cl, Giersch A, Boucart M, et al. Effects of lorazepam on vision and oculomotor balance. Binocul Vis Strabismus Q 2001;16:99-104.

15 Singh HK, Markowitz GD, Myers G. Esotropia associated with olanzapine. $J$ Clin Pharmacol 2000;20:488.

16 Mishra VN, Singh D. Diplopia due to phenothiazine toxicity. J Assoc Physicians India 1989;37:799.

17 Perez JG, Mato MP, Garcia AS, et al. Intraocular motility, electrophysiological tests and visual fields in drug addicts. Ophthal Physiol Opt 1995;15:493-8.

18 Burian HM, Miller JE. Comitant convergent strabismus with acute onset. Am J Ophthalmol 1958;45:55-63.

19 Wamsley JK, Palacios JM, Kuhar MJ. Autoradiographic localization of opioid receptors in the mammalian retina. Neurosci Lett 1981;27:19-24.

20 Freier BE, Pickwell LD. Physiological exophoria. Ophthalmic Physiol Optics 1983;3:267-72.

21 Hoyt CS, Good WV. Acute onset concomitant esotropia: when is it a sign of serious neurological disease? Br J Ophthalmol 1995;79:498-501.

22 Mays LE. Neural control of vergence eye movements: convergence and divergence neurons in midbrain. J Neurophysiol 1984;51:1091-108.

23 Judge SJ, Cumming BG. Neurons in the monkey midbrain with activity related to vergence eye movements and accommodation. J Neurophysiol 1986:55:915-30

24 Judge SJ. How is binocularity maintained during convergence and divergence? Eye 1996;10:172-6.

25 Gamlin PD. Neural mechanisms for the control of vergence eye movements. Ann NY Acad Sci 2002;956:264-72. 